\title{
Baudelaire y Ramón López Velarde
}

$E^{L}$ poeta más importante para el estudio de la literatura mexicana de este siglo es, sin duda, Ramón López Velarde. No por esto la crítica, género en el que tenemos verdaderos valores, ha tomado respecto a él una actitud definida; conocemos una serie de estudios, pequeños e insuficientes, que no han aportado casi nada al verdadero conocimiento del poeta. Si acaso, desde Guadalajara, Arturo Rivas Sáinz le ha dedicado un libro en el que, sobre todo, analiza al poeta jerezano desde el punto de vista técnico. Fuera de él no conocemos sino pequeños artículos publicados en revistas, prólogos y respuestas en notas de lectura, aparecidas al tiempo de una efemérides o con motivo de una publicación intrascendente.

Sin embargo, López Velarde es conocido por todos; "aun las minorías le han concedido rápidamente, antes de comprenderlo, una admiración gratuita y ciega", como asegura Xavier Villaurrutia en el prólogo a la selección El León y la Virgen - prólogo que había aparecido en la selección publicada por la Editorial "Cultura". Lo que demuestra la profunda raíz mexicana de la poesía de López Velarde, a la vez que la falta de disciplina literaria en nuestro medio, quizá la carencia de comprensión de lo mexicano en el momento actual, en que aún las influencias europeas llegan con algunos años de retraso.

Lo poco que se ha dicho al propósito, quizá también peque de injusto y de superficial, to que empeora la situación del elogiado poeta y la estabilidad de nuestra crítica literaria.

Sin embargo, algunas anotaciones se pueden sacar de dicha serie de artículos, algunas sugerencias certeras y hábiles que he pretendido reunir a la vez que ordenar en este pequeño estudio. Primero, un vistazo al problema amoroso en la poesía de López Velarde, 
no moral; segundo, una inspección a las posibles influencias americanas que señalan sus comentadores, y finalmente, en la tercera parte, algunas divagaciones sobre la analogía psicológica que algunos críticos han pretendido ver, o han encontrado, entre Ramón López Velarde y Carlos Baudelaire.

E1 tema es amplio y se halla tratado aquí de una manera esquemática; no pretendo en este estudio sino hacer un ordenamiento que considero necesario, dar mis ideas al respecto y aportar mi parte a la realización de una obra crítica que se realizará con el tiempo.

\section{El tema amoroso en Ramón López Velarde}

Tema eje de su insinuante poesía es, como en la mayoría de los poetas anteriores, el tema amoroso, que únicamente abandona en "La suave Patria" para lograr el poema de mayor aliento, el canto a su tierra. $Y$ tema eje, también, por ser visto siempre desde un ángulo personal que lo ha hecho distinguirse en la comparación con todos sus contemporáneos.

Ramón López Velarde, a primera vista, relaciona el amor con su idea religiosa, tema que veremos en un capítulo subsecuente. Sin embargo, y después de un detenido análisis, encontraremos facetas que nos ayuden al conocimiento de una verdad poética, lograda gracias a esas pequeñas fallas sentimentales, de gran interés para una biografía y su obra literaria, y que dieron origen a los cuatro breves volúmenes que la componen.

En La sangre devota tenemos conocimiento de la existencia de Fuensanta ("En el reinado de la primavera", "Cuaresmal", "Poema de vejez y de amor", "Canonización", "Hermana, hazme llorar"), que nos es presentada desde un aspecto distinto al de los poemas amorosos posteriores. Sin duda, Fuensanta fué el amor de provincia que dió materia a la iniciación poética de López Velarde, quien la ve como una futura esposa:

Yo te convido, dulce Amada, a que te cases con mi pena entre los vasos de cebada la última noche de novena...

e insiste; 
después la recuerda y la invoca en "Poema de vejez y de amor":
¡Oh, Fuensanta! Mi espiritu ayudado
de tus manos amigas,
ha de exhumar las glorias del pasado.
En el ropero arcaico están las ligas
que en el día nupcial fueron ofrenda
del abuelo amador
a la novia de rostro placentero,
y cada una tiene su leyenda:
"Tú fuiste, Amada, mi primer amor;
y serás el postrero" ... ;

poco después, en el mismo poema, la hace ajena a los fenómenos corporales :

$$
\begin{aligned}
& \text { Mas, joh Fuensanta!, al buen Jesús le pido } \\
& \text { que te preserve con su amor profundo: } \\
& \text { tus plantas no son hechas } \\
& \text { para los bailes frivolos del mundo } \\
& \text { sino para subir por el Calvario, } \\
& \text { y exento de pagano sensualismo } \\
& \text { el fulgor de tus ojos es el mismo } \\
& \text { que el de las brasas en el incensario....; }
\end{aligned}
$$

y más tarde, en "Canonización”, la consagra:

$$
\begin{aligned}
& \text { A tu virtud mi devoción es tanta } \\
& \text { que te miro en altar, como la santa } \\
& \text { Patrona que veneran tus zagales... }
\end{aligned}
$$

Pasado el tiempo de este amor, Ramón López Velarde inicia el tema que había de preocuparlo en toda su obra; desde luego, el amor idealizado ha perdido la realidad de la iniciación de su juventud y los problemas carnales, unidos al desasosiego de la insatisfacción, aparecen en un primer plano. El poeta ha llevado una esmerada educación cristiana en escuelas religiosas y se ha presentado en él el problema de conciencia ante los amores carnales. El mismo lo habría de lamentar en el poema "Que sea para bien", en que se entrega al pecado, justificándolo siempre con razones de amor imperioso:

Ya no puedo dudar. . . Diste muerte a mi cándida niñez, toda olorosa a sacristía, y también diste muerte al liviano chacal de mi cartuja... ; 
y sigue:

tu palidez denuncia que en tu rostro se ha posado el incendio $y$ ha corrido la lava...

y después :

te quedaste dormida en la vertiente

$$
\text { ... ¿o, quizá, }
$$

de un volcán, y la lava corrió sobre tu boca

y calcinó tu frente? ... :

$y$ finaliza :

yo estoy en la vertiente de tu rostro, esperando

las lavas repentinas que me den

un fulgurante goce.

Pero su problema de continencia no queda en él, lo hace extensivo; se preocupa ante las mujeres castas, bien las de provincia, castas por su larga estirpe de mujeres provincianas, o bien las mujeres castas por desprecio de los hombres; por incomprensión, doncellas, quizá por la viva fuerza. $Y$ por éstas sufre y lo expresa casi en toda su obra. En el poema "En la Plaza de Armas" se pregunta por las chiquillas compañeras de su infancia:

¿Son vírgenes intactas o madres dolorosas?

En “¿Qué será lo que espero?” expresa un deseo:

Si mi voto es que vivas dentro de una virginidad perenne y aromática, vuélvese un hondo enigma

lo que de ti persigue mi esperanza ... :

y termina con este verso final: "fragancia casta y ácida."

En "Tus hombros son como un ara" se repite:

¿Qué elocuencia, desvalida y casta, hay en tu persona que en un perenne desastre a las lágrimas convida? ... :

En "Para el zenzontle impávido..." se expresa con claridad:

y caigo en la lúgubre cuenta de que el zenzontle vive castamente, y su limpia virtud no ha de obtener un premio en Josafat....; 
declara :

$$
\begin{aligned}
& \text { Deploro su castidad reclusa } \\
& \text { y hasta le cedería uno de mis placeres... ; }
\end{aligned}
$$

más tarde reunimos el título del poema "Despilfarras el tiempo" a los primeros dos versos:

$$
\begin{aligned}
& \text { Prolóngase tu doncellez } \\
& \text { como una vacua intriga de ajedtez.... }
\end{aligned}
$$

después insiste:

$$
\text { despilfarras el tiempo y la emoción... }
$$

y tenemos a un López Velarde que mal aconseja para después arrepentirse. Peca para caer de rodillas siempre.

En el maravilloso poema "Memorias del circo", vuelve al tema de la doncella en prisión:

$$
\begin{aligned}
& \text { A las augustas Evas redivivas } \\
& \text { que niegan la migaja, pero inculcan } \\
& \text { en nuestra sangre briosa, una patética } \\
& \text { mendicidad de almendras fugitivas... }
\end{aligned}
$$

Pero no termina con las mujeres desde el punto de vista carnal ; su deseo siempre se espiritualiza. El, como poeta, termina siempre rezando; a ellas las relaciona con imágenes que las presentan desprovistas del cuerpo atrayente; las mata, las imagina siempre en estado de corrupción carnal. Al fin, por esto, las aconseja y las pone en la medida que se lo exige su conciencia moral, y de ello tenemos un fiel ejemplo en "Gavota":

Señor Dios mío: no vayas

a querer desfigurar

mi pobre cuerpo, pasajero

más que la espuma de la mar.

Ni me des enfermedad larga

en mi carne, que fué la carga

de la nave de los hechizos.

del dolor el aposento

y la genuflexión verídica

de tu trágico pavimento...; 
y después:

$$
\begin{aligned}
& \text { amé los talles zalameros } \\
& \text { y el virginal sacrificio; } \\
& \text { amé los ojos pendencieros } \\
& \text { y las frentes en armisticio. }
\end{aligned}
$$

En "A las vírgenes", poema clave para el estudio de esta preocupación de López Velarde, tenemos un claro ejemplo de cómo las entrega a la muerte:

$$
\begin{aligned}
& \text { ¿E1 tiempo se desboca; el torbellino } \\
& \text { os arrastra al fatal despeñadero } \\
& \text { de la Muerte; en las sombras adivino } \\
& \text { vuestro desnudo encanto volandero; } \\
& \text { y os quisieran ceñir mis manos fieles, } \\
& \text { por detener vuestra caída obscura } \\
& \text { con un lúbrico lazo de claveles } \\
& \text { lazado a cada virginal cintura! }
\end{aligned}
$$

Y por último, en el poema "Tus dientes" leemos el elogio de ese "nimio y pulcro litoral por donde navegan las sonrisas", para caer al final en las imágenes macabras:

Porque la tierra traga todo pulcro amuleto y tus dientes de ídolo han de quedarse mondos en la mueca erizada del hostil esqueleto, yo los recojo aquí, por su dibujo neto y su numen patricio, para el pasmo y la gloria de la humanidad giratoria.

¿Qué problema espiritual encontraba Ramón López Velarde en las mujeres, que le parecía tan suyo? ¿Qué castidad obligada los unía? Quizá, y esto lo veremos en capítulo subsecuente, la conciencia moral del poeta jerezano se hallaba probada a todas las fuerzas. Se hundía y emergía a la claridad. Quizá también por ello su muerte llegara a los treinta y tres años, que tanto presintiera y que lo uniera al fin con otras verdades. 


\section{Posibles influencias americanas}

Como señala Bernardo Ortiz de Montellano en un Esquema de la literatura mexicana moderna, "Ramón López Velarde es el intérprete de la provincia mexicana y de algunos rasgos del paisaje. Sensibilidad erótica y católica, un sobresalto de niño sorprendido en el pecado, consciente y temeroso entre el juicio de sus sentidos y el juicio final, pagano y creyente -antinomia que por razón histórica existe en nuestro pueblo-; religioso de los aspectos externos, sensuales, del catolicismo; ojos de acólito azorado entre los riesgos furtivos de una ciudad de pasiones que atormentan un corazón intacto de provincia. Poesía de complejos y timideces que busca, afanosamente, para expresarse con dignidad -aspecto mexicano de su lenguaje - los más complicados adjetivos, las palabras selectas".

Características todas éstas que han hecho pensar a nuestros críticos en relaciones y analogías con poetas europeos y americanos, anteriores a él o bien representantes de su mismo movimiento literario. Xavier Villaurrutia, en el prólogo que ya hemos mencionado, señala influencias de Leopoldo Lugones y Julio Herrera y Reissig, a la vez que de Luis Carlos López. Ortiz de Montellano, en la revista $R u e c a$ y en respuesta a Villaurrutia, añade nombres de autores franceses: Montaigne, Pascal y Anatole France; en su Esquema de la literatura mexicana moderna lo señala heredero de la castigada estética de Díaz Mirón.

No obstante barajar tantos poetas alrededor de López Velarde, poco se ha hecho por señalar de una manera más definitiva y audaz sus verdaderos puntos de contacto. Es cierto que el imponer una influencia implica una labor comparativa casi siempre aventurada y por lo regular errónea; en algunos casos es preferible establecer analogías de espíritu, de medio y de paisaje.

El camino más directo para llegar a un conocimiento de las influencias es el estudio de los libros que leyere el poeta, mejor que las opiniones escritas o de palabra. Hay quien dice que Ramón López Velarde gustaba de leer el poema "El ama", de Gabriel y Galán. El mismo López Velarde confiesa su interés por Carlos Baudelaire en el poema "Tenías un rebozo de seda", y más tarde se declara en un artículo admirador de Leopoldo Lugones, considerándolo como el más "hondo poeta de habla castellana". 
El colombiano Luis Carlos López parece haber sido leído por López Velarde ; en su poema "Medio ambiente" habla de la "Singer" (marca de la máquina de coser) con la misma ingenuidad y familiaridad con que lo hace nuestro poeta. Por otra parte, su poesía provinciana muestra paralelo con la de López Velarde, aunque las figuras y metáforas no tienen el menor punto de contacto.

En Leopoldo Lugones sí notamos una mayor cercanía de espíritu, aunque tampoco de estilo, ni menos aún de forma; si acaso en ejemplos como el siguiente, en el que no encontramos sino paridad en la consonancia y parecidos casuales:

En el "Himno a la Luna", de Leopoldo Lugones:

Luna, quiero cantarte

ioh ilustre anciana de las mitologías!

con toda la fuerza de mi arte... ;

y en otro sentido, en "La suave Patria" López Velarde se dirige a Cuauhtémoc:

Joven abuelo: escúchame loarte, único héroe a la altura del arte.

Como éste, podríamos encontrar ejemplos en distintos autores desconocidos los unos de los otros; sin embargo, no parece extraña la relativa influencia del argentino en López Velarde teniendo a la vista su confesión, y versos de imágenes parecidas, análogas quizá, que apuntamos en seguida:

Al rendirse tu intacta adolescencia, emergió, con ingenuo desaliño, tu delicado cuello, del corpiño anchamente floreado, en la opulencia.

Del salón solitario, mi cariño te brindaba su equívoca indulgencia. Sintiendo muy cercana la presencia del duende familiar, rosa y armiño.

Ascendí suspendido de tu beso...

Abrióse con erótica eficacia tu enagua de Surah... 


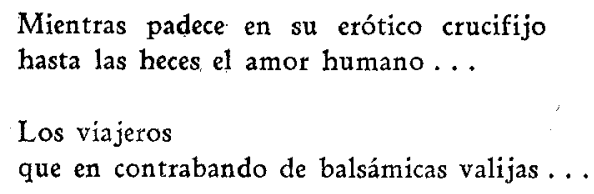

Más notoria es la influencia recibida de la obra poética de Julio Herrera y Reissig por nuestro poeta. (Hay que hacer notar que Lugones también parece haber sido influído por el uruguayo. A propósito de la aparición de Las montañas del oro Blanco-Fombona arremetió contra él, acusándolo de seguir formas y giros en el soneto tomados de los que publicó ya Herrera y Reissig en 1900, en algunas revistas.)

En la obra de Herrera y Reissig sí encontramos analogías en la forma y en la idea, inclusive versos que podrían firmar cualquiera de los dos poetas sin dejar abierta alguna rendija por donde pudieran ser reconocidos. En "El crepúsculo del martirio" leemos:

La cristiana

viudez de aquella hora en la campana;

en "El Ama".

Por cuanto el señor cura es más que un hombre, flota en el naufragio unánime su continencia lisa...

y en sus manos canónicas, golondrinas y grullas comulgan los recortes de las hostias que fríe...;

en el soneto del "Domingo":

IOh, domingo! La infancia de espíritu te sueña...;

y estos dos versos de "Desolación absurda":

una hurí desesperada

del harem de Baudelaire,

en los que menciona, como López Velarde, al poeta parnasiano. (Nótese cómo usa los términos "hurí" y "harem" que tanto gustaban a nuestro poeta.)

$\mathrm{Y}$ qué decir de "la grey que se empavesa de sacrílego adorno" de Reissig y "la grey astrosa" de López Velarde, y el perro de San Roque y de René, el perro que "hacía tres veces el camino yendo y viniendo desde ti hasta mí", y el perro del regreso de Herrera y Reis- 
sig, que "en ímpetus de lealtad amena describe coleando círculos de alegria". Así como del soneto de "La iglesia", con el que podriamos ejemplificar de un golpe:

En un beato silencio el recinto vegeta, las virgenes de cera duermen en su decoro de terciopelo lívido $y$ de esmalte incoloto: y San Gabriel se hastía de soplar la trompeta ...

Sedienta, abre su boca de mármol la pileta.

Una vieja estornuda desde el altar del coro...

y una legión de átomos sube un camino de oro aéreo. que una escala de Jacob interpreta.

Inicia sus labores el ama reverente:

para saber si anda de buenas San Vicente, con tímidos arrobos repica la alcancía...

Acá y allá maniobra después con un plumero, mientras, por una puerta que da a la sacristía, irrumpe la gloriosa turba del gallinero.

En los anteriores catorce versos no encontraríamos, sin una especial atención, la verdadera identidad de su autor (Herrera y Reissig), como no la encontraríamos en éstos, debidos a la pluma de López Velarde:

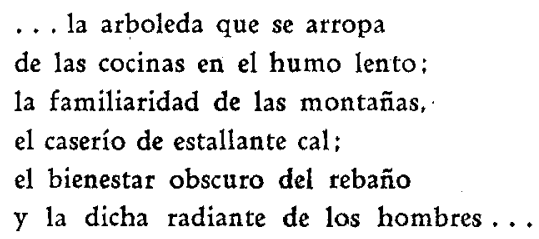

en cuya esencia encontramos la identidad de dos espíritus que, aun siguiendo la senda poética, tomaron caminos distintos enlazados por una especial unidad de espíritu. 


\section{Ramón López Velarde y Carlos Baudelaire}

Novalis, en sus Fragmentos, nos da una clave para el conocimiento de la obra poética de Charles Baudelaire:

"Tal vez se verifique una transformación si el hombre llegase a amar el mal del mundo: en el momento en que el hombre comenzase a amar la enfermedad o el dolor, hallaría en sus brazos la más encantadora voluptiosidad; se sentiría penetrado por el gozo más alto y positivo. ¿ No podría acaso ser la enfermedad un medio para llegar a una síntesis más elevada? ¿Cuanto más terrible fuese el dolor tanto mayor sería la voluptuosidad que éste encierra? Tođa enfermedad es, tal vez, el principio necesario del amor ... La enfermedad a medias es un mal; la enfermedad total, voluptuosidad: una voluptuosidad superior..." Así nos dice en su serie de fragmentos o gérmenes en los que entrega toda su verdad romántica.

En el caso anterior, el amor enfermedad; en el siguiente, el amor y la muerte: "Una unión que se concluye también para la muerte, es una boda que nos ofrece una compañera para la noche. En la muerte, el amor es lo más dulce; para el amante la muerte es la noche nupcial: un secreto de dulces misterios."

$\mathrm{Y}$ aun lo relaciona con el cristianismo: "El pecado es el gran estímulo para el amor de Dios. Cuanto más pecador uno se siente, se siente también más cristiano." Añade: "La unión incondicional con Dios, es el fin del pecado y del amor..." $Y$ finalmente, concluye: "Amor es absolutamente enfermedad; de aquí el significado maravilloso del cristianismo."

Indudablemente estos notables fragmentos coinciden con Baudelaire: en ambos la enfermedad, "el mal", la aceptación del dolor, la nostalgia del infinito y lo que llamaríamos "luz de la voluptuosidad" son motivos de inspiración; y esto también, por muy distintos que parezcan el "dandy" desgarrado de la peluca de color y el melancólico y sereno cantor de los "Himnos de la noche", como asegura Sánchez Barbudo en el prólogo a su selección y traducción de los Fragmentos.

Esta importante coincidencia, ¿ en qué se relaciona con Baudelaire? ¿Y qué relación existe entre el mismo autor de Las flores del mal con el autor de La Divina Comedia para que se le haya llamado Dante fragmentario? $Y$ en México, ¿por qué lo relacionamos con 
nuestro poeta López Velarde? ¿Qué íntima línea de ideas los une y los relaciona?

Xavier Villaurrutia, en su prólogo a la obra de López Velarde, nos presenta al poeta emparentado espiritualmente con Baudelaire y nos dice: "Ya he dicho que, según confesión expresa, gracias a Baudelaire descubrió López Velarde no sólo la rima, sino también y sobre tođo el olfato, el más característico, el más refinado, el más precioso y sensual de los sentidos que poeta alguno como Baudelaire haya puesto en juego jamás." B. Ortiz de Montellano, en la revista Rueca, responde a tal afirmación con las siguientes palabras: "El olfato a que se refiere López Velarde no representa el reconocimiento de la importancia que este sentido - el más espiritual- tiene en la estética de Baudelaire, sino el mexicano equivalente de malicia, apropiado a la inocente intención del poema." ("Tenías un rebozo de seda." "Entonces era yo seminarista - sin Baudelaire, sin rima y sin olfato.")

Pero las analogías más profundas las encuentra Villaurrutia en "la agonía, el vacío, el espanto y la esterilidad", y añade: "Si la religiosidad de López Velarde se resuelve en erotismo, siguiendo un camino inverso, pero no menos dramático, el erotismo de Baudelaire se convierte, en último extremo, en plegaria:

\section{Ah. Seigneut, donnez-moi la force et le coutage de contempler mon corps et mon coeur sans dégoût."}

Ortiz de Montellano encuentra diferencias básicas entre estos dos espíritus. "López Velarde - nos dice- vive sobre todo por la gracia de la mujer, por el encanto virginal de lo femenino que loa en numerosos versos con prolija vehemencia”, y añade: “. . para Baudelaire es la mujer, y escojo una de sus frases menos coléricas:

\section{La Circé tyranique aux dangereux parfums."}

Pero en lo que sí concuerdan los críticos es en la final "elevación mística" de los dos poetas y el parecido o "paralelismo que puede establecerse, más bien psicológico que estético, entre la poesía de Ramón López Velarde y la obra del poeta francés Carlos Baudelaire". 
No creo que en este caso se pueda hablar de influencias directas para establecer tal "paralelismo", pues por el contrario, creo en una analogía casual de ciertos sentimientos; inclusive me parece aventurada la idea lanzada por Ortiz de Montellano en el párrafo anterior. Los parecidos psicológicos los creo difíciles, máxime cuando la psicología de dos autores presenta características tan diferentes: el uno, Baudelaire, desesperado y amargado contra quienes no lo comprenden (véase Proyectos de prólogos para Las flores del mal, por ejemplo), blasfemo en ocasiones por angustias de todos géneros, se convierte en un pecador más alejado de la verdad cristiana. $\mathrm{E}$ l otro, López Velarde, siempre se encuentra sumiso a los cambios y a las sorpresas; apenas goza en el pecado se pone de rodillas a orar, conmovido por el arrepentimiento; no increpa a las mujeres, pues las ve cerca del ángel, las canoniza.

Si bien ambos revelan su interés espiritual en citas biblicas, en oraciones sagradas, Baudelaire nos dice en "Les phares":

Ces extases, ces cris, ces pleurs, ces te deum ...

En "La muse vénale" repite:

Chanter des te deum auxquels tu ne crois guere...

Utiliza ritmos de tipo "letanía", como los siguientes, en "Une charogne":

Etoile de mes yeux, soleil de ma nature, vous, mon ange et ma passion.... ;

o en el poema XLII:

A la très belle, a la très bonne, a la ttès chère....

así como con el uso de sugerencias bíblicas: Rey David, Babel, etc., no podemos establecer un parecido sino casual, pues no han sido los temas religiosos y bíblicos, tema a la mano de todos los poetas, con lo que podríamos establecer diferencias. Como tampoco'las podríamos establecer en la técnica, en la que López Velarde tendría mucho que aprender del poeta francés.

Es cierto, sin duda, que coinciden en la tesis usada por ambos de contraponer dos verdades opuestas o establecer contradicciones de orden caótico. En Baudelaire leemos en "Mon coeur mis a $n u$ ": 
"Tout enfant j'ai senti dans mon coeur deux sentiments contradictoires, l'horreur de la vie et l'extase de la vie", y en López Velarde encontramos, en un plano moral distinto, estos cuatro versos que se refieren a "La saltapared":

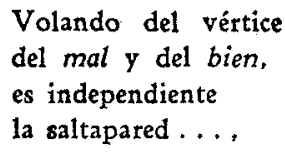

o la "simultaneidad sagrada y diabólica del universo" en "José de Arimatea".

Con lo que nos colocamos en el problema moral de ambos poetas, problema que, con mayor razón, creo, deberá ser objeto de estudio. De una manera indudable, López Velarde es un hombre consciente del mal como lo es Baudelaire; sin embargo, el primero tiene su problema moral fijado más claramente y con menos profundidad que el segundo; Baudelaire, inclusive, llega a hacer una romántica filosofia del mal. Volviendo a Novalis, anotaremos un razonamiento: "Cuanto más predomine en un hombre la tendencia del mal, tanto más bueno es naturalmente", y más aún el siguiente, con el que localizamos el espíritu de Batudelaire ante el mal: "Los malvados son arrastrados al mal por su odio contra los malos."

Con lo que podríamos concluir con Paul Valéry: "Il y a dans les meillers vers de Baudelaire une combinaison de chair y d'esprit", o con T. S. Eliot: "... existe para él una brecha entre el amor humano y el divino. Su amor humano es definido y positivo, su amor divino, vago e indeciso; de ahí su insistencia sobre el mal del amor, de ahí su vituperación constante de la hembra."

Con todo, Baudelaire y López Velarde sí se hallan unidos en un deseo de perdón, están unidos por un muy íntimo remordimiento; ambos tienen plegarias, y terminan en todos los casos rezando:

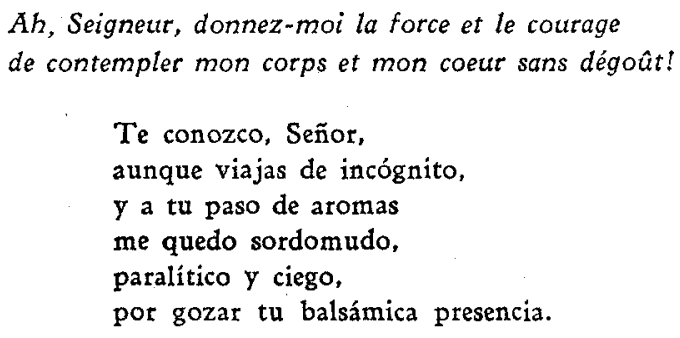


Dante señala los límites concretos del Bien y del Mal; Baudelaire y López Velarde, podríamos decir, lo siguen con un criterio cristiano. Sin embargo, estos límites humanos preocupan las conciencias desde las literaturas primarias; la manzana del árbol de la vida forma quizá la primera definición literaria de tales temas.

$\mathrm{Si}$ algo hace que la obra eche raíces, es preciso que posea valores humanos, y valor humano es la conciencia del Bien y del Mal. Por tanto, no me parece cualidad extraordinaria la posesión de esta conciencia, puesto que es valor fundamental en el hombre y su obra.

Bernardo Jiménez Montellano,
Universidad de México.

\section{B I B L IOGRA F A}

Charles BAudelaire, Proyectos de prólogo para Las flotes del mal (Les Fleuts du $\mathrm{Mal}$ ).

T. S. ELIOT, Los poetas metafisicos, y otros ensayos sobre teatro y religión.

JULIo HeRrera y ReIssig, El éxtasis de la montaña, Pascuas del tiempo, Los maitines de la noche.

luis Carlos López, De mi villotrio, Madrid.-Postutas difíciles, Pot el atajo, Cartagena, Colombia.

RAMÓN LÓPEZ VElARDE, La sangre devota, 1916.-Zozobra, 1919.-El minutero, 1924,-El son del corazón, 1932.

LEOPOLdO LUGONES, Los crepúsculos del jardin, Odas seculares, Poemas solariegos.

B. ORTIZ DE MONTEllANo, "Esquema de la literatura mexicana moderna", en Contempotáneos, 1931.-_Baudelaire y LLópez Velarde", en Rueca, núms. 11 y 12 .

ARTURo Rivas SÁrnz, "Concepto de la zozobra", en El Hijo Pródigo, núm. 10 , enero 1944.

JAIME TORRES BODET, "Literatura mexicana actual", en Contemporáneos, núm. 4.- "Cercanía de López Velarde", en Contemporáneos, núms. 28-29.

PAUL VALÉRY, "Baudelaire y su descendencia", en Revista de Occidente, núm. XII, año II.

Xavier Villaurrutia, Prólogo a El León y la Virgen, 1942. 
